\title{
Article
}

\section{Characterisation of aggregates of cyclodextrin-drug complexes using Taylor Dispersion Analysis}

Zaman, Hadar, Bright, Andrew G., Adams, Kevin, Goodall, David M. and Forbes, Robert Thomas

Available at http://clok.uclan.ac.uk/17676/

Zaman, Hadar, Bright, Andrew G., Adams, Kevin, Goodall, David M. and Forbes, Robert Thomas ORCID: 0000-0003-3521-4386 (2017) Characterisation of aggregates of cyclodextrin-drug complexes using Taylor Dispersion Analysis. International Journal of Pharmaceutics, 522 (1-2). pp. 98-109. ISSN 0378-5173

It is advisable to refer to the publisher's version if you intend to cite from the work. http://dx.doi.org/10.1016/j.ijpharm.2017.02.012

For more information about UCLan's research in this area go to http://www.uclan.ac.uk/researchgroups/ and search for <name of research Group>.

For information about Research generally at UCLan please go to http://www.uclan.ac.uk/research/

All outputs in CLoK are protected by Intellectual Property Rights law, including Copyright law. Copyright, IPR and Moral Rights for the works on this site are retained by the individual authors and/or other copyright owners. Terms and conditions for use of this material are defined in the policies page.

\section{CLoK}

Central Lancashire online Knowledge www.clok.uclan.ac.uk

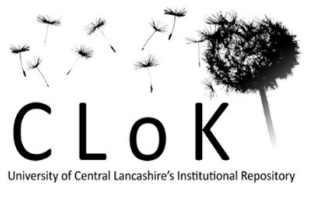


Characterisation of aggregates of cyclodextrin-drug complexes using Taylor Dispersion Analysis

Hadar Zaman ${ }^{1}$, Andrew G. Bright ${ }^{1}$, Kevin Adams ${ }^{1,2}$, David M. Goodall ${ }^{3 *}$ and Robert T. Forbes $^{1,4^{*}}$

${ }^{1}$ Faculty of Life Sciences, University of Bradford, Bradford BD7 1DP UK. ${ }^{2}$ Incanthera Ltd, 76 King Street, Manchester, M2 4NH, UK ${ }^{3}$ Paraytec Ltd, York House, Outgang Lane, Osbaldwick York, YO19 5UP, ${ }^{4}$ School of Pharmacy and Biomedical Sciences, University of Central Lancashire, Preston PR1 2HE UK (Tel +44 1772893513 email. rtforbes@uclan.ac.uk)*co-corresponding authors.

Footnote $\quad{ }^{4} \mathrm{P}$ resent address of corresponding author 


\section{ABSTRACT}

There is a need to understand the nature of aggregation of cyclodextrins (CDs) with guest molecules in increasingly complex formulation systems. To this end an innovative application of Taylor dispersion analysis (TDA) and comparison with dynamic light scattering (DLS) have been carried out to probe the nature of ICT01-2588 (ICT-2588), a novel tumor-targeted vascular disrupting agent, in solvents including a potential buffered formulation containing $10 \%$ hydroxypropyl- $\beta$-cyclodextrin. The two hydrodynamic sizing techniques give measurement responses are that fundamentally different for aggregated solutions containing the target molecule, and the benefits of using TDA in conjunction with DLS are that systems are characterised through measurement of both mass- and z-average hydrodynamic radii. Whereas DLS measurements primarily resolve the large aggregates of ICT01-2588 in its formulation medium, methodology for TDA is described to determine the size and notably to quantify the proportion of monomers in the presence of large aggregates, and at the same time measure the formulation viscosity. Interestingly TDA and DLS have also distinguished between aggregate profiles formed using HP- $\beta-C D$ samples from different suppliers. The approach is expected to be widely applicable to this important class of drug formulations where drug solubility is enhanced by cyclodextrin and other excipients.

Keywords:

Taylor Dispersion Analysis

Peptide prodrug

Aggregation

Cyclodextrin

Solubility enhancement

Formulation

\section{Introduction}

An understanding of the self-association behaviour and conformation change of a candidate drug in different environments is desirable towards its pharmaceutical development. Insight into drug-excipient interaction behaviour is also required. Rapid, costeffective techniques using small amounts or volumes of sample that can analyse a drug in a label-free and immobiliser-free solution are of high interest. It is also desirable to be able to rapidly screen a range of formulation buffers and characterise the increasingly complex formulations that are required to enhance solubility without the need for dilution. Size-based analysis and viscosity measurements are key parameters required in the early assessment of parenteral drugs with potential for aggregate formation. Taylor dispersion analysis (TDA) is a technique for measurement of diffusion coefficient and hydrodynamic radius, named after Sir 
Geoffrey Taylor who developed and provided the first practical test of the theory (Taylor, 1953). There is a considerable body of literature on methodology and applications of TDA, as exemplified for single component systems (Wakeham et al., 1976; Bello et al., 1994; Sharma et al., 2005; Cottet et al., 2007; d'Orlyé et al, 2008; Ribeiro et al., 2008) and mixtures (Kelly and Leaist, 2004; Cottet et al, 2007, 2010). An instrument utilizing UV imaging detection at two windows for samples flowing through a capillary has been developed specifically for TDA and complementary solution viscosity measurements, and applied for characterising proteins and their formulations (Hawe et al., 2011; Hulse and Forbes, 2011a, 2011b). Very high precision (RSD $<1 \%$ ) is obtained in protein sizing (Paraytec, 2010; Hulse and Forbes 2011b; Hulse et al., 2013). Use of methodology with two windows has the benefit that contributions to variance other than Taylor dispersion, e.g. those from injection, are automatically removed (Chamieh and Cottet, 2012; Ye et al., 2012; Hulse et al., 2013). The instrument has recently been used as an early developability screen of therapeutic antibody candidates (Lavoisier and Schlaeppi, 2015). The authors noted that the instrumental combination of hydrodynamic radius measurements from nanolitre quantities with solution viscosity measurements allowed screening of candidates with a view to the early identification of candidates with development issues.

A number of solubilisation strategies can be used to enhance the solubility of poorly soluble drugs (Douroumis and Fahr, 2013). For anti-cancer candidate drugs a range of technologies have been trialled for targetting and/or solubilisation purposes. These include the use of liposomes (Deshpande et al., 2013), polymer micelles (Richter et al., 2010), dendrimers (Svenson and Chauhan, 2008), and cyclodextrins (Gidwani and Vyas, 2015). Cyclodextrins are often used to increase drug solubility through complex formation (Uekama et al., 1998). The ability of cyclodextrins to self-associate and the role of cyclodextrin-drug complexes and aggregates in solubilisation and delivery of drugs have been well documented in a series of papers by Loftsson and coworkers amongst others (Loftsson and Brewster, 1996, 2012; Loftsson et al., 2002, 2004; Messner et al., 2010, 2011; Jansook et al., 2010; Loftsson, 2014). The body of work showed that solubilisation and stabilisation of drugs in aqueous CD formulations are strongly influenced by other commonly used excipients. Jansook et al. (2010) were able to conclude that CD solubilisation is also affected in combination formulations containing more than one drug and that $\mathrm{CD}$ formulation studies should always be performed in a medium that closely resembles the final drug formulation.

Given that subtle changes in the formulation buffer composition can affect solubilisation and aggregate formation, and that inclusion complexes as well as a range of sizes of aggregates can be present in aqueous complexation media, and that such compositions are concentration dependent (Messner et al., 2010), there is a need for analytical tools to characterise such systems and provide formulation fingerprints. Valente and Soderman (2014) affirm this view by pointing out that CD self-assembly is a fundamental issue that remains veiled or not completely clear in this promising field with plenty of challenges.

Physico-chemical methods used to characterise binding and aggregation in such systems include dynamic light scattering (DLS) and NMR. The use of microscopy in this field has been reviewed (He et al., 2008). Messner et al. (2010) highlighted some of the deficiencies of the various instruments including that NMR results can be difficult to 
interpret, especially when numerous atomic interactions are being investigated. When recently applied to the study of whether native cyclodextrins aggregate in water, three ${ }^{1} \mathrm{H}$ NMR techniques (NMR diffusometry, relaxometry, and proton peak intensity) showed that levels of large aggregates (> $100 \mathrm{CDs}$ ) were below the detection limit of $1 \%$ (Valente et al., 2015). Regarding DLS measurements, it has been commented that $R_{h}$ is obtained but not shape, it can be difficult to find acceptable laser intensity that produces reliable results, and concentrated solutions produce signal noise (Messner et al., 2010). From the above it is clear that a range of techniques and new tools are helpful in characterising such complexity.

TDA has been used to measure diffusion coefficients and hydrodynamic radii of cyclodextrins (Ribeiro et al., 2007, 2008). TDA methodology can also provide information on binding of guest molecules. With UV absorbing guest species and spectrophotometric detection, the diffusion constants of guest molecules have been investigated as a function of cyclodextrin concentration and binding curves obtained (De Azevedo et al., 2000) from which binding constants can be determined (Bielejewska et al., 2010; Jensen and Østergaard, 2010). Another approach has been to use a differential refractometer to measure mutual diffusion coefficients over a range of guest and host concentrations and fit these data (Barros et al., 2015; Filho et al., 2016).

Whilst binding can be studied in favourable cases, there have been no approaches using TDA to look at aggregation of cyclodextrin complexes. Addressing this challenge, the objective of the present work is to explore the use of a different methodological approach for TDA, alongside DLS, to provide mechanistic insight towards the nature of the solubilisation strategy for a poorly soluble drug candidate, and the aggregation behaviour of drug-CD complexes.

\section{Insert Fig. 1 here}

ICT01-2588 (Figure 1), originally referred to as ICT2588 (Gill et al., 2008), is a novel tumor-targeted vascular disrupting agent activated by membrane-type matrix metalloproteinases (Atkinson et al., 2010; Ansar et al., 2014) which has demonstrated preclinical therapeutic activity against solid tumors and reduced potential for cardiovascular toxicity (Gill et al., 2014). In this paper we report results of TDA experiments on ICT01-2588 in the solvents dimethylsulfoxide (DMSO), methanol, and TDA alongside complementary DLS studies in a potential formulation medium Tris buffer containing $10 \%$ hydroxypropyl- $\beta$ cyclodextrin.

\section{Materials and methods}

\subsection{Materials}


ICT01-2588 was provided by Incanthera Ltd (Bradford, UK). Methanol and dimethyl sulfoxide were purchased from Fisher Scientific UK Ltd (Loughborough, UK). Tris (tris(hydroxymethyl)aminomethane) and its hydrochloride salt (Trizma-base, Trizmahydrochloride), fluorescein disodium salt, Hellmanex III and a first sample of (2hydroxypropyl)- $\beta$-cyclodextrin (HP- $\beta$-CD), product code H107, were purchased from SigmaAldrich Ltd (Poole, UK). This first sample of HP- $\beta-C D$ was specified to have degree of substitution of 2-hydroxypropyl units $0.5-1.3$ per glucose unit and in this paper is referred to as HP- $\beta-C D-s 1$. A second sample of HP- $\beta-C D$, product code 1038870 , was obtained from Fisher Scientific Ltd (Loughborough, UK). This has specified degree of substitution of 2hydroxypropyl units 2-6, i.e. 0.3-1.0 per anhydroglucopyranose (glucose) unit, and is referred to as HP- $\beta$-CD-s2.

\subsection{Sample preparation}

ICT01-2588 was dissolved in methanol at $0.5 \mathrm{mg} / \mathrm{mL}$, and a series of two-fold dilutions were made to $0.03125 \mathrm{mg} / \mathrm{mL}$. ICT01-2588 was dissolved in DMSO at $1 \mathrm{mg} / \mathrm{mL}$, and subsequent two-fold dilutions made to $0.0625 \mathrm{mg} / \mathrm{mL}$. All solutions were freshly prepared prior to analysis using the Viscosizer 200.

Tris buffers were directly prepared to nominal $\mathrm{pH} 8.40$, by dissolving the appropriate amount of Trizma-HCl (264 mg) and Trizma-base (403 mg) in $100 \mathrm{~mL}$ distilled water. HP- $\beta$ CD was dissolved in Tris buffer $(\mathrm{pH} 8.40)$ to $0.10 \mathrm{~g} / \mathrm{mL} .5 .0 \mathrm{mg}$ of ICT01-2588 were dissolved by stirring overnight in $2 \mathrm{~mL}$ of the $0.1 \mathrm{~g} / \mathrm{mL}$ HP- $\beta-C D$ Tris buffer (pH 8.40), giving a stock solution of concentration $2.5 \mathrm{mg} / \mathrm{mL}$. Samples of ICT01-2588 each with total volume $400 \mu \mathrm{L}$ were prepared from this stock solution directly into the vials of the Viscosizer 200 autosampler by mixing $\mathrm{V} \mu \mathrm{L}$ stock and (400-V) $\mu \mathrm{L} 0.1 \mathrm{~g} / \mathrm{mL}$ HP- $\beta$-CD Tris buffer. With $\mathrm{V}=400,320,160,80$ and $40 \mu \mathrm{L}$, concentrations were $2.5,2.0,1.0,0.5$ and $0.25 \mathrm{mg} / \mathrm{mL}$, respectively. Samples of fluorescein disodium salt were prepared at mass concentrations 0.44 , 0.35 and $0.17 \mathrm{mg} / \mathrm{mL}$ in Tris buffer and Tris buffer with $0.1 \mathrm{~g} / \mathrm{mL}$ HP- $\beta-C D$.

\subsection{Taylor Dispersion Analysis}

\subsubsection{Instrumentation}

Instrumentation used was a Viscosizer 200 (Malvern Instruments, Malvern, UK), with a fused silica capillary $75 \mu \mathrm{m} \mathrm{ID,} 360 \mu \mathrm{m}$ OD, total length $130 \mathrm{~cm}$, lengths to the end of window 1 and window $245 \mathrm{~cm}$ and $85 \mathrm{~cm}$, respectively. The temperature for the measurements was set at $25.0^{\circ} \mathrm{C}$. Each series of runs was carried out with light selected using an optical filter at either 280 or $490 \mathrm{~nm}$. Stray light corrections were automatically made in software after initial measurements with the appropriate stray light test solution (4hydroxybenzoic acid $10 \mathrm{mg} / \mathrm{mL}$ in $0.1 \mathrm{M} \mathrm{NaOH}$ for $280 \mathrm{~nm}$; fluorescein disodium salt 10 $\mathrm{mg} / \mathrm{mL}$ in water for $490 \mathrm{~nm}$ ).

\subsubsection{Measurement of hydrodynamic radius}


The pulse injection mode was used for sizing (see Supplementary Information, Figure $\mathrm{S} 1)$. Sequences for the runs are given in Table 1.

\section{Insert Table 1 here}

Absorbance versus time data are automatically processed to obtain the diffusion coefficient, $D$, and hydrodynamic radius, $R_{\mathrm{h}}$.

The software determines peak centre times at the first and second window, $t_{1}$ and $t_{2}$ respectively, and the corresponding standard deviations, $\tau_{1}$ and $\tau_{2}$, and variances, $\tau_{1}{ }^{2}$ and $\tau_{2}{ }^{2}$. Variances and times are used to calculate $D$ and $R_{\mathrm{h}}$, using Eqs. 1, 2 and 3.

$\tau_{2}^{2}-\tau_{1}^{2}=r^{2}\left(t_{2}-t_{1}\right) / 24 D$

$D=k_{\mathrm{B}} T / 6 \pi \eta R_{\mathrm{h}}$

$R_{\mathrm{h}}=4 k_{\mathrm{B}} T\left(\tau_{2}^{2}-\tau_{1}^{2}\right) /\left(\pi \eta r^{2}\left(t_{2}-t_{1}\right)\right)$

where $k_{\mathrm{B}}$ is the Boltzmann constant, $T$ the absolute temperature, $\eta$ the viscosity of the solution, and $r$ the capillary radius.

\subsubsection{Measurement of viscosity}

Time difference data obtained in the pulse injection mode sizing experiments also allow measurement of relative viscosity, since the capillary with two windows serves as a capillary viscometer (Tanford, 1961; Paraytec, 2011; Ye et al., 2012). Poiseuille's law for the velocity of pressure-driven flow in a tube shows that

$v=\Delta x / \Delta t=r^{2} \Delta P / 8 \eta L$

where $v$ is the velocity, $\Delta x$ the distance and $\Delta t=t_{2}-t_{1}$ the time difference between the two windows, $\Delta P$ the pressure, and $L$ the length of the capillary. It is evident from Eq. (4) that if all other variables are constant, the time difference is directly proportional to the viscosity.

In the case where carrier solution and sample are prepared in the same solvent and a reference solution is run under the same pressure drive conditions

$\eta / \eta_{\mathrm{o}}=\eta_{\mathrm{rel}}=\Delta t / \Delta t_{\mathrm{o}}$

where $\eta_{\mathrm{o}}$ is the viscosity of the reference solution, $\eta$ the viscosity of the solvent and $\eta_{\text {rel }}$ is the relative viscosity. Runs with the reference solution (water containing trace amounts of caffeine) were typically carried out immediately before the sizing runs. This approach was used for confirmation of the viscosity of the solvents (methanol, DMSO) by comparison with literature values at the temperature of the measurements $\left(25.0^{\circ} \mathrm{C}\right)$. It was also used for determination of the viscosity of the potential formulation medium, Tris buffer containing $10 \%$ HP- $\beta$-CD. 


\subsubsection{Capillary wash protocols}

When using solutions containing HP- $\beta-C D$, where samples contained aggregates and problems with capillary blockage were noted in initial test experiments, a wash protocol using nitric acid and DMSO as reagents to remove any surface-adsorbed species and aggregates was used prior to each run sequence. During the final phase of these experiments, using fluorescein disodium salt as sample, an alternative capillary washing protocol was tested and found to give excellent results, so is detailed here. This involves the reagent Hellmanex III, which is widely used to clean fused silica spectrophotometer cells. At the beginning of the experiment, rinse with Hellmanex III (2\% v/v) at 2000 mbar for 45 min followed by a wash with water for $15 \mathrm{~min}$ at $2000 \mathrm{mbar}$. Between the runs for different concentrations in the series, rinse with Hellmanex III $(2 \% \mathrm{v} / \mathrm{v})$ at $2000 \mathrm{mbar}$ for $5 \mathrm{~min}$ followed by a wash with water at $2000 \mathrm{mbar}$ for $5 \mathrm{~min}$.

\subsection{Dynamic Light Scattering}

Dynamic light scattering experiments were carried out using a Zetasizer Nano ZS (Malvern Instruments Ltd., Worcestershire, UK; laser wavelength $633 \mathrm{~nm}$ ). Samples were analysed unfiltered. Appropriate detector settings were automatically determined by the instrument and three replicate measurements for each sample were performed at $25^{\circ} \mathrm{C}$ after an equilibration period of 10 minutes. The DLS instrument measures mutual diffusion coefficients, and hydrodynamic radii were derived from these using absolute viscosity values (c.f. equation 2) determined by the Viscosizer 200 as documented above. When calculating the volume average radius for HP- $\beta-C D$ in Tris buffer, refractive index values used were 1.330 for the dispersant and 1.570 for the material.

\section{Results and discussion}

\subsection{ICT01-2588 in DMSO and methanol}

\subsubsection{Sizing from Taylor Dispersion Analysis}

Sizing runs were carried out in DMSO and methanol at $280 \mathrm{~nm}$. Because of the differences in viscosity of the two solvents, the drive pressure was decreased from 140 mbar with DMSO to 70 bar with methanol to provide better comparability of run times. Examples are shown in Figure 2. At concentrations below $0.25 \mathrm{mg} / \mathrm{mL}$ in DMSO, and $0.125 \mathrm{mg} / \mathrm{mL}$ in methanol, the peaks were found to have anomalous profiles: this was attributed to a refractive index artefact from slight mismatch of solvent levels in sample and carrier media, which has greater effect the smaller the peak.

Insert Fig. 2 here. 
Results for fitting Gaussian peak profiles to give hydrodynamic radius, as described in the Experimental section, are summarized in Table 2. The literature values for the viscosity (0.544 mPa s for methanol, Xiang et al., 2006), $1.992 \mathrm{mPa}$ s for DMSO (Ciocirlan and Julian, 2009) were used in calculation of hydrodynamic radii using equation (3). The measured difference in time between the two windows, relative to that for the reference solution water containing a trace of caffeine (see Eq. (5), gave viscosities for ICT01-25588 in methanol $0.530 \pm 0.007 \mathrm{mPa} \mathrm{s}(\mathrm{n}=20)$ and in DMSO $2.025 \pm 0.023 \mathrm{mPa} \mathrm{s}(\mathrm{n}=10)$, in satisfactory agreement with the literature values.

For DMSO, relative standard deviations in the hydrodynamic radius within a set of 5 replicate runs are less than $2 \%$ at the two highest concentrations, but increase on decreasing the concentration as the peak amplitudes become smaller. There is no evidence for any trend in variation of radius with concentration, and this suggests that ICT01-2588 is present as a monomeric species in DMSO. The average of all radii in DMSO is $1.23 \pm 0.06 \mathrm{~nm}$.

In methanol, whilst values of the radius at two concentrations seem slightly lower than those in DMSO, the average of all radii $1.14 \pm 0.13 \mathrm{~nm}$ is within the range of uncertainty not significantly different from the value in DMSO.

In previous work (Ansari et al, 2014), molecular modeling of the linker in ICT012588, defined as the peptide sequence with the N-terminal masking group containing fluorescein isothiocyanate (i.e. everything aside from the C-terminal colchicine group in Fig. 1), gave length $2.6 \mathrm{~nm}$. This is consistent with radius 1.1-1.2 nm observed for ICT01-2588 by the present TDA sizing study.

Gaussian peak profile fitting also gives data for peak areas. Peak area measurements are of relevance in checking for self-consistency, that the amount of sample seen at the two windows is the same as the amount injected, and that there is no loss e.g. due to adsorption on the walls. To address the fact that there has been no formal treatment of this in any previous papers on TDA, theory linking peak area with injection time, sample concentration and absorption coefficient is presented in the supplementary information. The methodology was used to compare areas for ICT01-2588 in experiments at the same wavelength, $280 \mathrm{~nm}$, in DMSO, methanol, and Tris buffer containing 10\% HP- $\beta$-CD. Self-consistency was demonstrated across the solvent media, and the absorption coefficient at $280 \mathrm{~nm}$ (Table S1) shown to accord with the sum of the absorption coefficients of the functional groups (Table S2).

It should be noted that at all concentrations studied ICT01-2588 is below its solubility limit, which in methanol is $\sim 0.6 \mathrm{mg} / \mathrm{mL}$. The solubility of ICT01-2588 in water is approx. 15 $\mu \mathrm{g} / \mathrm{mL}$, as estimated from area under the curve from HPLC data fitted to a standard curve.

Insert Table 2 here

\subsection{ICT01-2588 and fluorescein in Tris buffer with $10 \% \mathrm{HP}-\beta-C D$}

\subsubsection{Solubilisation of ICT01-2588}

ICT01-2588 has very limited solubility in water and aqueous buffer solutions. A potential formulation medium under exploration is a $\mathrm{pH} 8.4$ Tris buffer with $10 \%$ HP- $\beta$-CD. 
A photograph of samples of ICT01-2588 at nominal concentration $1 \mathrm{mg} / \mathrm{mL}$ in this medium, prepared with HP- $\beta-C D-s 2$, and in water and in Tris buffer is shown in Fig. 3. Little of the ICT01-2588 sample is seen to have dissolved in water, whereas the material is fully solubilised at concentration $1 \mathrm{mg} / \mathrm{mL}$ in the Tris buffer with $10 \% \mathrm{HP}-\beta-\mathrm{CD}$ and has the characteristic colour and tint of the chromophoric fluorescein end group in the structure (Fig. 1).

\section{Insert Fig. 3 here}

\subsubsection{Taylor Dispersion Analysis profiles for ICT01-2588}

TDA runs were carried out at a range of concentrations using the protocols for sizing as shown in Table 1. Fig. 4a illustrates sizing records from one run sequence over the range 0.25 to $2.5 \mathrm{mg} / \mathrm{mL}$ ICT01-2588 in $\mathrm{pH} 8.4$ Tris buffer with $10 \%$ of the HP- $\beta$-CD-s1. It is evident that the TDA results are qualitatively completely different from those when the compound is prepared in methanol or DMSO (Fig. 2). As the concentration increases, a component which has a front running at twice the velocity of the central peak and slowly decays with time increasingly dominates the profile of absorbance versus time. This is characteristic of a relatively large species with sub-micron particle size which has zero diffusion on the timescale of the experiment (Taylor, 1953; Latunde-Dada et al., 2015). Latunde-Dada et al. (2015) exemplified the transition between pure convection and early time dispersion using a series of polystyrene latex standards with $R_{\mathrm{h}} 100,200$ and $300 \mathrm{~nm}$ in experiments on the Viscosizer 200 instrument. A predominantly convective profile was observed for the $200 \mathrm{~nm}$ standard at a run pressure of $250 \mathrm{mbar}$, with the front arriving at window 1 at $100 \mathrm{~s}$, whilst at 18 mbar pressure a normal TDA Gaussian profile was obtained. The run pressure for transition between pure convection and early time dispersion profiles scales inversely with hydrodynamic radius.

At $0.25 \mathrm{mg} / \mathrm{mL}$ the peaks similar to those of monomer are seen as the dominant feature at the two windows. At $2.5 \mathrm{mg} / \mathrm{mL}$, at the first window the front has higher amplitude than the Gaussian type peak. There is very good reproducibility of all of the profiles from the set of 5 replicates (see supplementary information, Fig. S2). From comparison of the results at all 5 concentrations studied, $0.25,0.5$, 1, with the front arriving 2 and $2.5 \mathrm{mg} / \mathrm{mL}$, the area at window 1 of the Gaussian peak is seen to remain qualitatively constant whilst the amplitude of the front increases systematically with increasing concentration.

\section{Insert Fig. 4 here}

When runs were carried out using the second HP- $\beta-C D$ sample, HP- $\beta-C D-s 2$, for sample formulation and as the carrier liquid in the sizing experiments, significant differences in behaviour were observed by comparison with the first HP- $\beta-C D$ sample, HP- $\beta-C D-s 1$. Runs in $\mathrm{pH} 8.4$ Tris buffer with $10 \%$ of the HP- $\beta$-CD-s2 were carried out at two wavelengths, 280 and $490 \mathrm{~nm}$, and the same behaviour was observed at both wavelengths. Fig. 4b shows concentration dependence at the 5 concentrations $0.25,0.5,1.2$ and $2.6 \mathrm{mg} / \mathrm{mL}$ and the results of 5 replicate experiments. At $2.5 \mathrm{mg} / \mathrm{mL}$, at the first window the front has much 
lower amplitude than the Gaussian type peak. The amplitudes of both the front and the Gaussian peak increase with increasing ICT01-2588 concentration.

\subsubsection{Viscosity of the formulation medium}

For determining viscosity, required to make the conversion from diffusion coefficient to hydrodynamic radius (c.f. Eqs. (1) and (2)), the time difference between the centre of the narrow peak ascribed to non-aggregated species was compared to that for runs with water containing trace amounts of caffeine carried out immediately before or after the sequence, as described in Eq. (5). From all of the runs with $10 \%$ HP- $\beta$-CD-s 1 , there was extremely high reproducibility in the time difference, and the viscosity was determined to be $1.301 \pm 0.028$ $\mathrm{mPa}$ s. From all the runs with HP- $\beta$-CD-s2, the viscosity was determined to be $1.301 \pm 0.035$. The fact that both values are identical shows that there is no difference between the the two HP- $\beta$-CD samples with regard to viscosity.

\subsubsection{Hydrodynamic radius and percentage of non-aggregated form of ICT01-2588}

Data fitting was carried out using theory for convective diffusion (Latunde-Dada et al., 2015). An example is shown in Fig. 5.

\section{Insert Fig. 5 here}

Table 3 collects together the quantitative findings from Taylor dispersion analysis and convective diffusion theory for 125 runs, giving the hydrodynamic radius and percentage of the non-aggregated form of ICT01-2588. Results for $\%$ area are given for window 1 . As previously discussed from qualitative inspection of the traces, the first HP- $\beta$-CD sample, HP$\beta$-CD-s1 has different behaviour from the second sample, HP- $\beta-C D-s 2$. For HP- $\beta$-CD-s1, the peak area of the non-aggregated form increases by only a factor 2 over the 10 fold range of concentration $0.25-2.5 \mathrm{mg} / \mathrm{mL}$. This means that its percentage of the total area systematically decreases as the concentration of ICT01-2588 increases, from 79 to $14 \%$ in going from 0.25 to $2.5 \mathrm{mg} / \mathrm{mL}$. By contrast, with HP- $\beta$-CD-s 2 the percentage area for the non-aggregated form of ICT01-2588 is between 58 and $100 \%$ at $0.25 \mathrm{mg} / \mathrm{mL}$, and is also high at the highest concentrations, being in the range $72-81 \%$ at 2 and $2.5 \mathrm{mg} / \mathrm{mL}$ for the $1^{\text {st }}, 2^{\text {nd }}$ and $3^{\text {rd }}$ run sequence. Unlike all the other sequences, where the runs were carried out from low to high concentration and typically spanned a total time of ... hours, the $4^{\text {th }}$ sequence had measurements taken from high to low concentration over this time duration, and there appeared to be rather low percentages of the non-aggregated form in the high concentration runs at the beginning of the sequence.

\section{Insert Table 3 here}

Hydrodynamic radius values are all within a narrow range, $1.27-1.42 \mathrm{~nm}$, for the non-aggregated form measured in HP- $\beta$-CD-s 2 at the two highest concentrations in the $1^{\text {st }}$, $2^{\text {nd }}$ and $3^{\text {rd }}$ run sequences. There is also broad consistency across all runs with both HP- $\beta-C D-$ $\mathrm{s} 1$ and HP- $\beta-\mathrm{CD}-\mathrm{s} 2$, with radius in the range 1.27-1.92 $\mathrm{nm}$ for all measurements where the 
percentage of non-aggregated form was in excess of 50\%. The average of all radii for ICT012588 in HP- $\beta$-CD-s2 where the non-aggregated form is $>50 \%$ of the total is $1.32 \pm 0.07 \mathrm{~nm}$. This is somewhat higher than the average radius $1.19 \pm 0.10 \mathrm{~nm}$ in DMSO and methanol (Table 1). Since ICT01-2588 is present as a monomer in these solvents, results are consistent with the non-aggregated form of ICT01-2588 also being a monomer in HP- $\beta-\mathrm{CD}$, though with complexation to HP- $\beta-\mathrm{CD}$ causing a slight addition to the radius. Analogous findings are reported for fluorescein in HP- $\beta$-CD later in this section, and further discussion will be presented in the section dealing with the nature of the aggregation.

From the entries in Table 3, for both forms of HP- $\beta$-CD where the percentage of nonaggregated form of ICT01-2588 is $<50 \%$, there is seen to be a general increase in average radius with decrease in $\%$ non-aggregated form. With \% non-aggregated form given in square brackets, values of average radius are 2.2-2.9 $\mathrm{nm}$ [49-40\%], 3.2-3.6 nm [39-30\%], $6.8 \mathrm{~nm}$ [29-20\%], 4.6-5.0 nm [19-10\%].

This increase in radius could be in part due to time-dependent changes during travel between the two windows. For runs with significant levels of aggregate, data fitting using convective diffusion theory with a single monomer component results in good fitting at window 1, but the fitting at window 2 is less satisfactory (see e.g. Fig. 5). Also, the area for the non-aggregated form increases between the two windows. These observations in the 2 window TDA measurements could be indicative of kinetic effects, moving the system to rebalancing the monomer-aggregate equilibrium position during pressure-driven flow in the capillary. The aggregate, driven purely by convective flow, is distributed over a far greater length of the capillary than the monomer, where Taylor dispersion ensures that the species occupies a fairly narrow zone. A schematic diagram, illustrating the conditions in Fig. 5, is given in Figure 6. The mixture injected has $80 \%$ aggregate, A, and 20\% monomer, $\mathrm{M}$. The front of the aggregate distribution travels at twice the velocity of the average of the flow and monomer peak, and has a concentration profile in space retaining the triangular shape and time profile of the injection zone at the front and then tracking back to zero in a linear fashion as distance decreases. The monomer has a Gaussian profile centred at $45 \mathrm{~cm}$ when it reaches window 1, and this broadens by further Taylor dispersion corresponding to window 2 centred at $85 \mathrm{~cm}$. At this point the front of the aggregate profile has already exited the $130 \mathrm{~cm}$ capillary. The relative concentrations of aggregate and monomer can be seen at all distances, and it is evident that $\mathrm{M} / \mathrm{A}>1$ at the maxima but $\mathrm{M} / \mathrm{A}=0$ outside the Gaussian bands. This imbalance relative to the starting relative concentrations $M / A=20 / 80$ is suggested as the driver for rebalancing the monomer-aggregate equilibrium, with the greater time to window 2 than to window 1 allowing more time for reequilibration which distorts the observed peak profile as seen in Fig. 6 away from the ideal of Fig. 5. If aggregate size steadily decreases during reequilibration, the larger size of the aggregate for ICT01-2588 in HP- $\beta$-CD-s1 than in HP- $\beta$-CD-s2 (see DLS results in subsequent section, 3.2.6) could be consistent with differences between the two cyclodextrins seen in the TDA experiments, since a minimum hydrodynamic radius of $\sim 100 \mathrm{~nm}$ is needed for a convective diffusion profile under the conditions of Fig. 5. 


\subsubsection{Hydrodynamic radius for fluorescein in Tris buffer and Tris buffer with $10 \%$ HP- $\beta$-CD}

Noting references to self-aggregation of cyclodextrins (Loftsson and Brewster, 1996, 2012; Loftsson et al., 2002, 2004; Messner et al., 2010, 2011; Jansook et al., 2010; Loftsson, 2014; He et al. 2008), sizing experiments were carried out with fluorescein in the same carrier medium as that for ICT01-2588, $\mathrm{pH} 8.4$ Tris buffer with 10\% HP- $\beta$-CD-s2, and also in the Tris buffer without any added cyclodextrin. Fluorescein, conjugated to the peptide sequence via an isothiocyanate linker, is one of the functional end groups of ICT01-2588 (see Fig. 1). Mass concentrations of fluorescein disodium salt $(0.44,0.35,0.17 \mathrm{mg} / \mathrm{mL})$ were chosen to give molar concentrations similar to those for ICT01-2588 at the three highest concentrations $(2.5,2.0$ and $1.0 \mathrm{mg} / \mathrm{mL})$, and wavelengths used were 280 or $490 \mathrm{~nm}$. There was no evidence from the Taylor dispersion profiles for any aggregation, and a singlecomponent Gaussian fitted well to all observed profiles.

All hydrodynamic radius measurements for fluorescein disodium salt in Tris buffer and Tris buffer with $10 \%$ HP- $\beta$-CD is presented in the Appendix, Table S3. From the results in Tris buffer, TDA was found to give hydrodynamic radius with excellent reproducibility (all RSDs less than 2\%). As expected, there was no dependence on detection wavelength, with values for $R_{\mathrm{h}}$ measured at 280 and $490 \mathrm{~nm}, 0.531 \pm 0.007 \mathrm{~nm}$ and $0.527 \pm 0.006 \mathrm{~nm}$ respectively, the same within the error limits. There was also no dependence on concentration. The viscosity value for water, $0.8905 \mathrm{mPa} \mathrm{s}$, was the input value for the calculations using Eq. (3).

From the time difference between the two windows in the Tris buffer with $10 \%$ HP- $\beta$ CD-s2, the viscosity $(1.30 \mathrm{mPa} \mathrm{s})$ was found to be identical to that measured in the experiments with ICT01-2588 (1.301 $\mathrm{mPa} \mathrm{s}$, see section 3.2.3), and this value was used in the calculations for $R_{\mathrm{h}}$ (Eq. (3)) in this carrier medium. The average hydrodynamic radius obtained for fluorescein in Tris buffer with $10 \%$ HP- $\beta$-CD from these TDA experiments over the three concentrations was $0.825 \pm 0.028 \mathrm{~nm}$. This $R_{\mathrm{h}}$ value is substantially greater than for fluorescein in Tris buffer, $0.529 \pm 0.006 \mathrm{~nm}$, and also greater than the value of $0.76 \mathrm{~nm}$ for the hydrodynamic radius of HP- $\beta$-CD in water (Ribeiro et al., 2007). The $56 \%$ increase in effective radius for fluorescein is consistent with binding to HP- $\beta-C D$ in a host-guest complex, as discussed in a subsequent part of this paper (section 3.3).

Unlike in section 3.2.4 where TDA gives definitive evidence for aggregation of ICT01-2588 in Tris buffer with 10\% HP- $\beta-\mathrm{CD}$, there is no evidence from any of the Taylorgrams or TDA experiments reported in this section that fluorescein by itself is present in an aggregate or promotes self-aggregation of the cyclodextrin.

\subsubsection{Dynamic Light Scattering for ICT01-2588 in Tris buffer with $10 \%$ HP- $\beta-C D$}

Dynamic light scattering measurements were made on ICT01-2588 at concentration $2.5 \mathrm{mg} / \mathrm{mL}$ in Tris buffer with $10 \%$ HP- $\beta$-CD-s1, the first HP- $\beta$-CD sample. Subsequently a more extensive series of measurements was carried out using the second HP- $\beta-C D$ sample. Solutions of ICT01-2588 at two concentrations 2.5 and $0.25 \mathrm{mg} / \mathrm{mL}$ were characterised in Tris buffer with $10 \%$ HP- $\beta$-CD-s2. Reference measurements were made at the same time on the buffer with 10\% HP- $\beta$-CD-s2. Results are given in Fig. 7 and Table 4. 
Insert Fig. 7 here

Insert Table 4 here

A qualitative comparison from Fig. 7 shows that ICT01-2588 has higher z-average radius in HP- $\beta-C D-s 1$ than in HP- $\beta-C D-s 2$, and that there is no contribution from any nonaggregated species to the z-average intensity distribution for either sample. Quantitatively, results in Table 4 show that the z-average radius for $2.5 \mathrm{mg} / \mathrm{mL}$ ICT01-2588 in HP- $\beta$-CD-s1 is a factor 5 greater than that in HP- $\beta-C D-s 2,728 \mathrm{~nm}$ vs. $144 \mathrm{~nm}$. There is no change in radius with concentration in going from 2.5 to $0.25 \mathrm{mg} / \mathrm{mL}$.

There is no suggestion of any non-aggregated species in these DLS data for ICT012588, despite the fact that the TDA sizing results discussed in section 3.2.4 show substantial proportions of monomeric ICT01-2588 in equilibrium with the aggregate.

The explanation for the different results from the two techniques is that DLS reports intensity-weighted size distributions, whereas mass-weighted size distributions are obtained from TDA. Because scattering intensity typically scales with the sixth power of radius Malvern Instruments, 2011), high radius species are extremely strongly weighted in DLS.

It is only in the case of the reference measurements on the solvent, Tris buffer with $10 \%$ HP- $\beta$-CD-s 2 , that a substantial proportion $(42 \%)$ of a low radius species $(0.72 \mathrm{~nm})$ is present in the intensity distribution. The size distribution by volume gives $100 \%$ of the low radius species, with volume mean hydrodynamic radius $0.67 \mathrm{~nm}$. These hydrodynamic radii from DLS provide a satisfactory match to the literature value of $0.76 \mathrm{~nm}$ (Ribeiro et al, 2007) for the molecule present in highest concentration, HP- $\beta-C D$.

Dynamic light scattering measurements were also made for fluorescein in the same solvent, Tris buffer with 10\% HP- $\beta$-CD-s2. The z-average radius was $187 \mathrm{~nm}$, and there was a small proportion $(18 \%)$ of a low radius species $(0.72 \mathrm{~nm})$. By contrast, as discussed in section 3.2 .5 , TDA gave $100 \%$ of the low radius species $(0.825 \mathrm{~nm})$, and this mass-weighted distribution gave no evidence for any aggregates. This is an important point to note when using DLS to characterise aggregates in cyclodextrins, suggesting that DLS intensity measurements need to be complemented by other techniques (see e.g. He et al., 2008) to avoid overweighting the contributions of aggregates to the overall distributions.

\subsection{Nature of aggregation}

\subsubsection{ICT01-2588 binding to HP- $\beta-C D$}

Taken together, the results from TDA and DLS suggest that in HP- $\beta$-CD there is a bimodal distribution between monomer and aggregate forms of ICT01-2588. The monomer is likely to itself be a distribution over free- and cyclodextrin-bound species, since ICT012588 has both end groups and side-chain groups in the linker which bind to cyclodextrins.

In this section, literature results on solubilisation and binding to cyclodextrins of individual groups in ICT01-2588 are considered and used to estimate fractions bound to HP$\beta$-CD. The five potential binding groups are indicated by arrows in Fig. 1. Phase-solubility 
analysis has been carried out for colchicine binding to HP- $\beta-C D$, studying solubility as a function of cyclodextrin concentration over the range in phosphate buffered saline ( $\mathrm{pH} 7.4)$ containing various concentrations of HP- $\beta-\mathrm{CD}\left(\mathrm{M}_{\mathrm{w}} \sim 1600 ; 30-180 \mathrm{mM}\right)$ based on the maximum solubility of HP- $\beta-\mathrm{CD}\left(50 \% \mathrm{w} / \mathrm{v}\right.$ at $\left.25^{\circ} \mathrm{C}\right)$ in water (Chauhan et al., 2013). Solubility was found to increase in a linear fashion, indicative of 1:1 binding classified as $A_{L}$ type according to nomenclature introduced by Higuchi and Connors (1965), and a binding constant, $K$, of $310 \mathrm{M}^{-1}$ reported (Chauhan et al., 2013). Assuming no change to $K$ when colchicine is the end group in the structure of Fig. 1 , the fraction bound, $f_{\mathrm{b}}$, can be calculated using the equation

$f_{\mathrm{b}}=K C /(1+K C)$

together with the value of the binding constant as above and the molar concentration $C=$ $7.2 \times 10^{-2} \mathrm{M}$, which corresponds to HP- $\beta-\mathrm{CD}$ at mass concentration $10 \% \mathrm{w} / \mathrm{v}$. This approach gives $f_{\mathrm{b}}=0.96$ and suggests that the colchicine would be present mostly bound to cyclodextrin.

Whilst no data are available for HP- $\beta-C D$ solubilisation or binding for other groups in ICT01-2588, binding constants, $K$, with $\beta$-CD have been documented for fluorescein, $360 \mathrm{M}^{-}$ ${ }^{1}$ (Flamigni, 1993), tyrosine, $48 \mathrm{M}^{-1}$ (Bekos et al., 1996), phenylalanine, $85 \mathrm{M}^{-1}$ (Kahle and Holzgrabe, 2004) (no value available for homophenylalanine). Assuming $K$ values for HP- $\beta$ $\mathrm{CD}$ are similar to those for $\beta-\mathrm{CD}$, and comparability between groups either free or part of the ICT01-2588 sequence, estimates of the fractions bound can be made using Eq. (6). Values are $f_{\mathrm{b}}>0.8$ for all groups considered individually, indicating that the proportion of cyclodextrinbound groups is always greater than the free proportion. For fluorescein, where $f_{b}=0.96$, the calculation is consistent with results reported in section 3.2.5, where the value of hydrodynamic radius of fluorescein in $10 \% \mathrm{w} / \mathrm{v} \mathrm{H}-\beta-\mathrm{CD}$ measured using TDA was shown to be far greater than that for free fluorescein. Other studies using TDA with UV detection to monitor drug binding to cyclodextrins (Bielejewska et al., 2010; Jensen and Østergaard, 2010) offer similar conclusions.

Formulae for cases where drugs bind more than one cyclodextrin are given in papers by Loftsson et al. (2004) and Loftsson and Brewster (2012). Distribution calculations (data not shown) suggest that the highest fractions of the population of ICT01-2588 species involve multiple bound CDs, and may indicate that the hydrophilic, highly water soluble cyclodextrin HP- $\beta$-CD helps solubilise ICT01-2588 through binding to more than one of the end or side chain groups.

\subsubsection{Aggregation}

The types of aggregation in cyclodextrin drug systems have been extensively researched and reviewed by Loftsson and his collaborators (Loftsson and Brewster, 1996, 2012; Loftsson et al., 2002, 2004; Messner et al., 2010, 2011; Jansook et al., 2010; Loftsson, 2014), Supramolecular assemblies of amphiphilic cyclodextrins alone or in self-assembled mixtures with other molecules of therapeutic significance are described in a recent review by Zerkoune et al. (2014). A bis-adamantine molecule which binds cyclodextrins at both ends 
and forms a hydrophilic $\beta$-cyclodextrin bis-inclusion complex has been shown to selfassemble into supramolecular vesicles (Nayak and Gopidas, 2015).

For HP- $\beta$-CD-s1, our TDA experiments suggest a monomer-aggregate equilibrium with a fairly constant concentration of monomer accompanied by increasing levels of aggregate across the 10-fold increase of drug concentration. Monomer-aggregate equilibria with similar characteristics, where the monomer concentration is the critical aggregation concentration, are exemplified in work on liposomes and vesicles by Nardin et al. (2000) and Chécot et al. (2002).

For HP- $\beta-C D-s 2$, aggregates are smaller in size than with HP- $\beta-C D-s 1$ and proportions of ICT01-2588 monomer are high even at high total drug concentration.

Differences between the Taylor dispersion profiles (or Taylorgrams, Cottet et al., 2010 ), of the two HP- $\beta$-CD samples may in part be due to one of them, HP- $\beta-C D-s 2$, specified to contain levels of up to $3 \% \beta-\mathrm{CD}$. There are also differences in the specified degree of substitution. $\beta-C D$ and $H P-\beta-C D$ vary in their solubility and drug binding characteristics, and for HP- $\beta-C D$ binding constants have also been noted to differ with changes in degree of substitution (Penn et al., 1994). The ability to rapidly obtain such Taylorgrams which can serve as 'fingerprint' characterisation of drug and CD aggregation states with formulation composition is useful in a quality by design approach to identifying product critical quality attributes.

In future work with ICT01-2588, it may be of interest to carry out systematic studies varying the cyclodextrin concentration, complementing TDA and DLS by using phase solubility methods to establish the concentration dependence of solubility to help establish the nature of the binding and the number of HP- $\beta$-CD molecules bound per ICT01-2588 unit. Other questions of interest concern time and shear dependence of the monomer-aggregate equilibrium: these dynamic factors are amenable to probing by TDA by varying the flow and shear rates.

\section{Conclusion}

The need for new analytical tools to deliver understanding of drug self-association and drugexcipient interaction in complex media is of great interest towards producing quality pharmaceutical products. Adding to our awareness of growing formulation complexity, literature in the last decade or so has moved our thinking from viewing CD complexation as a simple binding of a lipophilic drug moiety to a hydrophilic CD cavity to more complex models that can involve the self-association of CD molecules and CD complexes themselves. The findings we present highlight the ready use of TDA to explore the self-association of a peptide containing potential drug molecule in a range of solvents including a formulation where excipient association is possible. This study of a candidate drug molecule ICT01-2588 has shown the benefits of using Taylor dispersion analysis in conjunction with dynamic light scattering to characterise systems through measurement of both mass- and z-average hydrodynamic radii. Both viscosity of the solvent or formulation medium and hydrodynamic radius of the candidate drug are determined. Crucially, TDA provides the unique ability to see and quantify the proportion of monomers in presence of large aggregates of ICT01-2588 
in its formulation medium containing $10 \% \mathrm{HP}-\beta-\mathrm{CD}$. This is not possible using DLS, where the aggregates dominate the scattering signal response. TDA and DLS have also allowed distinction between aggregates formed using HP- $\beta$-CD samples from different suppliers. The approach is expected to be of wide applicability to this important class of systems where drug solubility is enhanced by cyclodextrin and other excipients. The ability to explore formulation design space of complex systems and progress rapid quality by design protocols is of great promise in helping us gain a clear view of these complex but highly useful systems.

\section{Acknowledgements}

We acknowledge support from Malvern Instruments to the University of Bradford for loan of a Viscosizer 200, to Tom Allen at Paraytec for experimental contributions, and to staff at Malvern Instruments in particular Seyi Latunde-Dada for assistance with some of the data fitting, and to Oksana Barker for her input.

\section{References}

Ansari, C., Tikhomirov, G.A., Hong, S.H., Falconer, R.A., Loadman, P.M., Gill, J.H., Castaneda, R., Hazard, F.K., Tong, L., Lenkov, O.D., Felsher, D.W., Rao, J., DaldrupLink, H.E., 2014. Development of novel tumor-targeted theranostic nanoparticles activated by membrane-type matrix metalloproteinases for combined cancer magnetic resonance imaging and therapy. Small 10, 566-575. doi:10.1002/smll.201301456

Atkinson, J.M., Falconer, R.A., Edwards, D.R., Pennington, C.J., Siller, C.S., Shnyder, S.D., Bibby, M.C., Patterson, L.H., Loadman, P.M., Gill, J.H., 2010. Development of a novel tumor-targeted vascular disrupting agent activated by membrane-type matrix metalloproteinases. Cancer Res. 70, 6902-6912. doi:10.1158/0008-5472.CAN-10-1440

Barros, M.C.F., Ramos, M.L., Burrows, H.D., Esteso, M.A., Leaist, D.G., Ribeiro, A.C.F., 2015. Ternary mutual diffusion coefficients of aqueous $\{1$-dopa $(1)+\beta-\mathrm{CD}(2)\}$ solutions at $\mathrm{T}=298.15 \mathrm{~K}$. J. Chem. Thermodyn. 90, 169-173. doi:10.1016/j.jct.2015.06.022

Bekos, E.J., Gardella, J.A., Bright, F.V., 1996. The binding of free oligopeptides to cyclodextrins: The role of the tyrosine group. J. Incl. Phenom. Mol. Recognit. Chem. 26, 185-195. doi: 10.1007/Bf01053537

Bello, M.S., Rezzonico, R., Righetti, P.G., 1994. Use of Taylor-Aris dispersion for measurement of a solute diffusion coefficient in thin capillaries. Science 266, 773-776. doi:10.1126/science.266.5186.773

Bielejewska, A., Bylina, A., Duszczyk, K., Fiałkowski, M., Holyst, R., 2010. Evaluation of ligand-selector interaction from effective diffusion coefficient. Anal. Chem. 82, 54635469. doi:10.1021/ac1008207 
Chamieh, J., Cottet, H., 2012. Comparison of single and double detection points Taylor Dispersion Analysis for monodisperse and polydisperse samples. J. Chromatogr. A 1241, 123-127. doi:10.1016/j.chroma.2012.03.095

Chauhan, R., Madan, J., Kaushik, D., Sardana, S., Pandey, R.S., Sharma, R., 2013. Inclusion complex of colchicine in hydroxypropyl- $\beta$-cyclodextrin tenders better solubility and improved pharmacokinetics. Pharm. Dev. Technol. 18, 1-10. doi:10.3109/10837450.2011.591801

Chécot, F., Lecommandoux, S., Gnanou, Y., Klok, H.A., 2002. Water-soluble stimuliresponsive vesicles from peptide-based diblock copolymers. Angew. Chemie - Int. Ed. 41, 1339-1343. doi:10.1002/1521-3773(20020415)41:8<1339::AIDANIE1339>3.0.CO;2-N

Ciocirlan, O., Iulian, O., 2009. Density, viscosity and refractive index of the dimethyl sulfoxide + o-xylene system. J. Serbian Chem. Soc. 74, 317-329. doi:10.2298/JSC0903317C

Cottet, H., Biron, J.-P., Martin, M., 2007. Taylor dispersion analysis of mixtures. Anal. Chem. 79, 9066-9073. doi:10.1021/ac071018w

Cottet, H., Martin, M., Papillaud, A., Souaïd, E., Collet, H., Commeyras, A., 2007. Determination of dendrigraft poly-L-lysine diffusion coefficients by Taylor dispersion analysis. Biomacromolecules 8, 3235-3243. doi:10.1021/bm070268j

Cottet, H., Biron, J.-P., Cipelletti, L., Matmour, R., Martin, M., 2010. Determination of individual diffusion coefficients in evolving binary mixtures by Taylor dispersion analysis: Application to the monitoring of polymer reaction. Anal. Chem. 82, 17931802. doi:10.1021/ac902397x

De Azevedo, M.B.M., Alderete, J.B., Lino, A.C.S., Loh, W., Faljoni-Alario, A., DurÁn, N., 2000. Violacein/ $\beta$-cyclodextrin inclusion complex formation studied by measurements of diffusion coefficient and circular dichroism. J. Incl. Phenom. Macrocycl. Chem. 37, 67-74. doi:10.1023/A:1008186706573

Deshpande, P.P., Biswas, S., Torchilin, V.P., 2013. Current trends in the use of liposomes for tumor targeting. Nanomedicine (Lond) 8, 1-32. doi:10.2217/nnm.13.118

d'Orlyé, F., Varenne, A., Gareil, P., 2008. Determination of nanoparticle diffusion coefficients by Taylor dispersion analysis using a capillary electrophoresis instrument. J. Chromatogr. A 1204, 226-232. doi:10.1016/j.chroma.2008.08.008

Douroumis, D., Fahr, A., editors. 2013. Drug delivery strategies for poorly water-soluble drugs. Advances in Pharmaceutical Technology Series. New Jersey, Wiley.

Filho, C.M.C., Verissimo, L.M.P., Valente, A.J.M., Ribeiro, A.C.F., 2016. Limiting diffusion coefficients of sodium octanoate, and octanoic acid in aqueous solutions without and with $\alpha$-cyclodextrin. J. Chem. Thermodyn. 94, 234-237. doi:10.1016/j.jct.2015.11.013 
Flamigni, L., 1993. Inclusion of fluorescein and halogenated derivatives in $\alpha-, \beta-$, and $\gamma-$ cyclodextrins. A steady-state and picosecond time-resolved study. 1993. J. Phys. Chem. 97, 9566-9572. doi: 10.1021/j100140a006

Gidwani, B., Vyas, A., 2015. A comprehensive review on cyclodextrin-based carriers for delivery of chemotherapeutic cytotoxic anticancer drugs. Biomed Res. Int. 2015. doi: $10.1155 / 2015 / 198268$

Gill J.H., Loadman, P.M., Falconer, R.A., Patterson, L.H., Atkinson, J.M., Bibby, M.C., 2008. MMP activated vascular disrupting agents, EP20120160556.

Gill, J.H., Loadman, P.M., Shnyder, S.D., Cooper, P., Atkinson, J.M., Ribeiro Morais, G., Patterson, L.H., Falconer, R.A., 2014. Tumor-targeted prodrug ICT2588 demonstrates therapeutic activity against solid tumors and reduced potential for cardiovascular toxicity. Mol. Pharm. 11, 1294-1300. doi:10.1021/mp400760b

Hawe, A., Hulse, W.L., Jiskoot, W., Forbes, R.T., 2011. Taylor dispersion analysis compared to dynamic light scattering for the size analysis of therapeutic peptides and proteins and their aggregates. Pharm. Res. 28, 2302-2310. doi:10.1007/s11095-011-0460-3

He, Y., Fu, P., Shen, X., Gao, H., 2008. Cyclodextrin-based aggregates and characterisation by microscopy. Micron 39, 495-516. doi:10.1016/j.micron.2007.06.017

Higuchi, T., Connors, K.A., 1965. Phase solubility techniques. Adv. Anal. Chem. Instrum. 4, $117-122$.

Hulse, W.L., Forbes, R.T., 2011a. A nanolitre method to determine the hydrodynamic radius of proteins and small molecules by Taylor dispersion analysis. Int. J. Pharm. 411, 64-68. doi:10.1016/j.ijpharm.2011.03.040

Hulse, W., Forbes, R., 2011b. A Taylor dispersion analysis method for the sizing of therapeutic proteins and their aggregates using nanolitre sample quantities. Int. J. Pharm. 416, 394-397. doi:10.1016/j.ijpharm.2011.06.045

Hulse, W.L., Gray, J., Forbes, R.T., 2013. Evaluating the inter and intra batch variability of protein aggregation behaviour using Taylor dispersion analysis and dynamic light scattering. Int. J. Pharm. 453, 351-357. doi:10.1016/j.ijpharm.2013.05.062

Kahle, C., Holzgrabe, U., 2004. Determination of binding constants of cyclodextrin inclusion complexes with amino acids and dipeptides by potentiometric titration. Chirality 16, 509-515. doi:10.1002/chir.20068

Kelly, B., Leaist, D.G., 2004. Using Taylor dispersion profiles to characterise polymer molecular weight distributions. Phys. Chem. Chem. Phys. 6, 5523. doi:10.1039/b412659a

Jansook, P., Kurkov, S. V., Loftsson, T. (2010), Cyclodextrins as solubilizers: Formation of complex aggregates. J. Pharm. Sci., 99: 719-729. doi: 10.1002/jps.21861 
Jensen, H., Østergaard, J., 2010. Flow induced dispersion analysis quantifies noncovalent interactions in nanoliter samples. J. Am. Chem. Soc. 132, 4070-4071. doi:10.1021/ja100484d

Latunde-Dada, S., Bott, R., Hampton, K., Leszczyszyn, O.I., 2015. Application of the exact dispersion solution to the analysis of solutes beyond the limits of Taylor dispersion. Anal. Chem. 87, 8021-8025. doi:10.1021/acs.analchem.5b02159

Lavoisier, A., Schlaeppi, J.M., 2015. Early developability screen of therapeutic antibody candidates using Taylor dispersion analysis and UV area imaging detection. MAbs 7, 77-83. doi:10.4161/19420862.2014.985544

Loftsson, T., 2014. Self-assembled cyclodextrin nanoparticles and drug delivery. J. Incl. Phenom. Macrocycl. Chem. 80, 1-7. doi:10.1007/s10847-013-0375-1

Loftsson, T., Brewster, M.E., 1996. Pharmaceutical applications of cyclodextrins. 1. Drug solubilization and stabilization. J. Pharm. Sci. 85, 1017-1025. doi:10.1021/js950534b

Loftsson, T., Brewster, M.E., 2012. Cyclodextrins as functional excipients: Methods to enhance complexation efficiency. J. Pharm. Sci. 101, 3019-3032. doi:10.1002/jps.23077

Loftsson, T., Magnúsdóttir, A., Másson, M., Sigurjónsdóttir, J.F., 2002. Self-association and cyclodextrin solubilization of drugs. J. Pharm. Sci. 91, 2307-2316. doi:10.1002/jps. 10226

Loftsson, T., Másson, M., Brewster, M.E., 2004. Self-association of cyclodextrins and cyclodextrin complexes. J. Pharm. Sci. 93, 1091-1099. doi:10.1002/jps.20047

De Azevedo, M.B.M., Alderete, J.B., Lino, A.C.S., Loh, W., Faljoni-Alario, A., Durán, N. 2000 . Violacein/ $\beta$-cyclodextrin inclusion complex formation studied by measurements of diffusion coefficient and circular dichroism. J. Incl. Phenom. Macrocycl. Chem. 37, 67-74. doi: 10.1023/A:1008186706573

Malvern Instruments, 2011. Dynamic light scattering common terms defined. White paper.

Messner, M., Kurkov, S. V., Jansook, P., Loftsson, T., 2010. Self-assembled cyclodextrin aggregates and nanoparticles. Int. J. Pharm. 387, 199-208. doi:10.1016/j.ijpharm.2009.11.035

Messner, M., Kurkov, S. V., Flavià-Piera, R., Brewster, M.E., Loftsson, T., 2011. Selfassembly of cyclodextrins: The effect of the guest molecule. Int. J. Pharm. 408, 235247. doi:10.1016/ j.ijpharm.2011.02.008

Nardin, C., Hirt, T., Leukel, J., Meier, W., 2000. Polymerized ABA triblock copolymer vesicles. Langmuir 16, 1035-1041. doi: 10.1021/la990951u

Nayak, N., Gopidas, K.R., 2015. Unusual self-assembly of a hydrophilic $\beta$-cyclodextrin inclusion complex into vesicles capable of drug encapsulation and release. J. Mater. Chem. B 3, 3425-3428. doi:10.1039/c4tb02114b 
Paraytec, 2010. Application Note AN015. Precision and accuracy of protein size determination using the ActiPix TDA200 Nano-Sizing System

Paraytec, 2011. Technical Note TN014. Determining sample viscosity in Taylor dispersion experiments

Penn, S.G., Bergström, E.T., Goodall, D.M., Loran, J.S., 1994. Capillary electrophoresis with chiral selectors: Optimization of separation and determination of thermodynamic parameters for binding of tioconazole enantiomers to cyclodextrins. Anal. Chem. 66, 2866-2873. doi:10.1021/ac00090a012

Ribeiro, A.C.F., Santos, C.I.A.V, Valente, A.J.M., Ascenso, O.S., Lobo, V.M.M., Burrows, H.D., Cabral, A.M.T.D.P.V., Veiga, F.J.B., Teijeiro, C., Esteso, M.A., 2008. Some transport properties of $\gamma$-cyclodextrin aqueous solutions at (298.15 and 310.15) K, J. Chem. Eng. Data 53, 755-759. doi 10.1021/je700598v

Ribeiro, A.C.F., Valente, A.J.M., Santos, C.I.A.V, Prazeres, P.M.R.A., Lobo, V.M.M., Burrows, H.D., Esteso, M.A., Cabral, A.M.T.D.P.V., Veiga, F.J.B., 2007. Binary mutual diffusion coefficients of aqueous solutions of $\alpha$-cyclodextrin, 2-hydroxypropyl- $\alpha$ cyclodextrin, and 2-hydroxypropyl- $\beta$-cyclodextrin at temperatures from (298.15 to 312.15) K. J. Chem. Eng. Data 52, 586-590. doi:10.1021/je060474z

Sharma, U., Gleason, N.J., Carbeck, J.D., 2005. Diffusivity of solutes measured in glass capillaries using Taylor's analysis of dispersion and a commercial CE instrument. Anal. Chem. 77, 806-813. doi:10.1021/ac048846z

Tanford, C., 1961. Physical chemistry of macromolecules, Wiley \& Sons, New York

Taylor, G., 1953. Dispersion of soluble matter in solvent flowing slowly through a tube. Proc. R. Soc. A Math. Phys. Eng. Sci. 219, 186-203. doi:10.1098/rspa.1953.0139

Valente, A.J.M., Carvalho, R.A., Söderman, O., 2015. Do cyclodextrins aggregate in water? Insights from NMR experiments. Langmuir 31, 6314-6320. doi:10.1021/acs.langmuir.5b01493

Wakeham, W.A., Salpadoru, N.H., Caro, C.G., 1976. Diffusion coefficients for protein molecules in blood serum. Atherosclerosis 25, 225-235. doi:10.1016/00219150(76)90029-0

Xiang, H.W., Laesecke, A., Huber, M.L., 2006. A new reference correlation for the viscosity of methanol. J. Phys. Chem. Ref. Data 35, 1597-1620. doi:10.1063/1.2360605

Ye, F., Jensen, H., Larsen, S.W., Yaghmur, A., Larsen, C., Østergaard, J., 2012. Measurement of drug diffusivities in pharmaceutical solvents using Taylor dispersion analysis. J. Pharm. Biomed. Anal. 61, 176-183. doi:10.1016/j.jpba.2011.11.030

Zerkoune, L., Angelova, A., Lesieur, S., 2014. Nano-assemblies of modified cyclodextrins and their complexes with guest molecules: Incorporation in nanostructured membranes and amphiphile nanoarchitectonics design. Nanomaterials 4, 741-765. doi:10.3390/nano4030741 
Click here to download Supplementary Material: Supplementary information vs8 14Dec2016submitted.docx 


\section{Tables}

Table 1. Sequences for Viscosizer 200 runs

\begin{tabular}{cccc}
\hline Method & Sequence & $\begin{array}{c}\text { Pressure } \\
(\mathrm{mbar})\end{array}$ & $\begin{array}{c}\text { Time } \\
(\mathrm{min})\end{array}$ \\
\hline Sizing & Rinse (carrier) & 2000 & 1 \\
& Fill (carrier) & 2000 & 1 \\
& Reset Baseline & 140 & 1 \\
& Load (sample) & 50 or $140^{\mathrm{a}}$ & 0.2 \\
& Dip (carrier) & 0 & 0.15 \\
& Run (carrier) & $140^{\mathrm{a}}$ & $\mathrm{n} / \mathrm{a}^{\mathrm{b}}$ \\
\hline
\end{tabular}

${ }^{a}$ In methanol, a set of runs was completed with 70 mbar used for both load and run steps. For ICT01-2588 in Tris buffer containing $10 \%$ HP- $\beta-C D$ as carrier, 300 mbar was used for both load and run steps. For fluorescein disodium salt in Tris buffer and Tris buffer containing $10 \% \mathrm{HP}-\beta-\mathrm{CD}$ as carrier, $140 \mathrm{mbar}$ was used for both load and run steps.

${ }^{\mathrm{b}}$ Sizing runs are automatically ended after the peak has passed the second window. 
Table 2. Hydrodynamic radius for ICT01-2588 in DMSO and methanol as a function of concentration. $\mathrm{n}=5$ at each concentration.

\begin{tabular}{ccc}
\hline \multirow{2}{*}{$\begin{array}{c}\text { ICT01-2588 } \\
\text { conc }(\mathrm{mg} / \mathrm{mL})\end{array}$} & \multicolumn{2}{c}{$R_{\mathrm{h}}(\mathrm{nm})$} \\
\cline { 2 - 3 } & $\mathrm{DMSO}$ & Methanol \\
\hline 1.00 & $1.174 \pm 0.010$ \\
0.50 & $1.266 \pm 0.016$ & $1.138 \pm 0.067$ \\
0.25 & $1.292 \pm 0.035$ & $1.006 \pm 0.018$ \\
0.125 & & $1.270 \pm 0.038$ \\
\hline
\end{tabular}


Table 3. Hydrodynamic radius and \% area at window 1 for the non-aggregated form of ICT01-2588 over the concentration range $0.25-2.5 \mathrm{mg} / \mathrm{mL}$ in $\mathrm{pH} 8.4$ Tris buffer with $10 \%$ HP- $\beta$-CD. Two HP- $\beta$-CD samples used: Sigma-Aldrich H107 (s1); Fisher Scientific 1038870 (s2), and two wavelengths for detection 490 and $280 \mathrm{~nm} . \mathrm{n}=5$ at each concentration. All sequences run from low to high concentration, except $4^{\text {th }}$ with HP- $\beta$-CD-s 2 which was high to low.

\begin{tabular}{|c|c|c|c|c|c|c|c|}
\hline & \multicolumn{2}{|c|}{$\begin{array}{l}\text { ICT01-2588 concentration } \\
\qquad(\mathrm{mg} / \mathrm{mL})\end{array}$} & 0.25 & 0.50 & 1.0 & 2.0 & 2.5 \\
\hline $\begin{array}{l}\text { Order in run } \\
\text { sequence }\end{array}$ & $\begin{array}{l}\text { Wavelength } \\
\quad(\mathrm{nm})\end{array}$ & $\begin{array}{l}\text { HP- } \beta-C D \\
\text { sample }\end{array}$ & \multicolumn{5}{|c|}{$\begin{array}{l}\text { Radius }(\mathrm{nm}) \\
{[\% \text { area }]}\end{array}$} \\
\hline $1^{\mathrm{st}}$ & 490 & s1 & $\begin{array}{c}1.40 \pm 0.06 \\
{[79 \pm 6]}\end{array}$ & $\begin{array}{c}1.92 \pm 0.11 \\
{[62 \pm 3]}\end{array}$ & $\begin{array}{c}3.58 \pm 1.20 \\
{[32 \pm 1]}\end{array}$ & $\begin{array}{c}4.56 \pm 0.50 \\
{[18 \pm 1]}\end{array}$ & $\begin{array}{c}5.01 \pm 0.40 \\
{[14 \pm 0]}\end{array}$ \\
\hline $1^{\text {st }}$ & 280 & s2 & $\begin{array}{c}1.27 \pm 0.11 \\
{[100 \pm 0]}\end{array}$ & $\begin{array}{c}1.29 \pm 0.02 \\
{[100 \pm 0]}\end{array}$ & $\begin{array}{c}1.23 \pm 0.01 \\
{[88 \pm 3]}\end{array}$ & $\begin{array}{c}1.34 \pm 0.02 \\
{[72 \pm 1]}\end{array}$ & $\begin{array}{c}1.35 \pm 0.02 \\
{[73 \pm 1]}\end{array}$ \\
\hline $2^{\text {nd }}$ & 280 & $\mathrm{~s} 2$ & $\begin{array}{c}1.47 \pm 0.07 \\
{[58 \pm 9]}\end{array}$ & $\begin{array}{c}2.24 \pm 0.22 \\
{[40 \pm 6]}\end{array}$ & $\begin{array}{c}1.28 \pm 0.01 \\
{[91 \pm 4]}\end{array}$ & $\begin{array}{c}1.26 \pm 0.03 \\
{[76 \pm 2]}\end{array}$ & $\begin{array}{c}1.35 \pm 0.03 \\
{[79 \pm 1]}\end{array}$ \\
\hline $3^{\text {rd }}$ & 490 & $\mathrm{~s} 2$ & $\begin{array}{c}1.65 \pm 0.07 \\
{[62 \pm 9]}\end{array}$ & $\begin{array}{c}2.72 \pm 0.12 \\
{[46 \pm 5]}\end{array}$ & $\begin{array}{c}2.94 \pm 0.09 \\
{[42 \pm 2]}\end{array}$ & $\begin{array}{c}1.27 \pm 0.08 \\
{[77 \pm 1]}\end{array}$ & $\begin{array}{c}1.42 \pm 0.04 \\
{[81 \pm 1]}\end{array}$ \\
\hline $4^{\text {th }} *$ & 490 & $\mathrm{~s} 2$ & $\begin{array}{c}1.68 \pm 0.06 \\
{[60 \pm 5]}\end{array}$ & $\begin{array}{c}2.42 \pm 0.06 \\
{[47 \pm 3]}\end{array}$ & $\begin{array}{c}2.59 \pm 0.09 \\
{[40 \pm 3]}\end{array}$ & $\begin{array}{c}6.82 \pm 0.64 \\
{[24 \pm 1]}\end{array}$ & $\begin{array}{c}3.29 \pm 0.41 \\
{[32 \pm 8]}\end{array}$ \\
\hline
\end{tabular}

*This sequence run from high to low concentration 
Table 4. DLS measurements for Tris buffer with 10\% HP- $\beta-C D$ and solutions of ICT01-2588 in Tris buffer with 10\% HP- $\beta$-CD. Two HP- $\beta$-CD samples used: Sigma-Aldrich H107 (s1); Fisher Scientific 1038870 (s2). Viscosity $1.301 \mathrm{mPa}$ s used in data processing. $\mathrm{n}=3$ for each sample.

\begin{tabular}{|c|c|c|c|c|}
\hline \multirow[b]{2}{*}{ Cyclodextrin in Tris buffer } & \multirow[b]{2}{*}{$\begin{array}{c}\text { ICT01-2588 concentration } \\
(\mathrm{mg} / \mathrm{mL})\end{array}$} & \multicolumn{3}{|c|}{ Radius (nm) } \\
\hline & & z-ave & $\begin{array}{c}\text { Peak 1 } \\
\text { [percent] }\end{array}$ & $\begin{array}{c}\text { Peak 2 } \\
\text { [percent] }\end{array}$ \\
\hline $10 \% \mathrm{HP}-\beta-\mathrm{CD}-\mathrm{s} 1$ & 2.5 & $728 \pm 17$ & $\begin{array}{l}936 \pm 65 \\
{[98 \pm 3]}\end{array}$ & $\begin{array}{c}62 \pm 108 \\
{[2 \pm 3]}\end{array}$ \\
\hline $10 \% \mathrm{HP}-\beta-\mathrm{CD}-\mathrm{s} 2$ & 2.5 & $144 \pm 2$ & $\begin{array}{c}163 \pm 2 \\
{[100]}\end{array}$ & - \\
\hline $10 \% \mathrm{HP}-\beta-\mathrm{CD}-\mathrm{s} 2$ & 0.25 & $141 \pm 2$ & $\begin{array}{c}157 \pm 3 \\
{[100]} \\
\end{array}$ & - \\
\hline $10 \% \mathrm{HP}-\beta-\mathrm{CD}-\mathrm{s} 2$ & 0 & $72 \pm 22$ & $\begin{array}{c}114 \pm 2 \\
{[58 \pm 1]}\end{array}$ & $\begin{array}{l}0.72 \pm 0.01 \\
{[42 \pm 1]}\end{array}$ \\
\hline
\end{tabular}




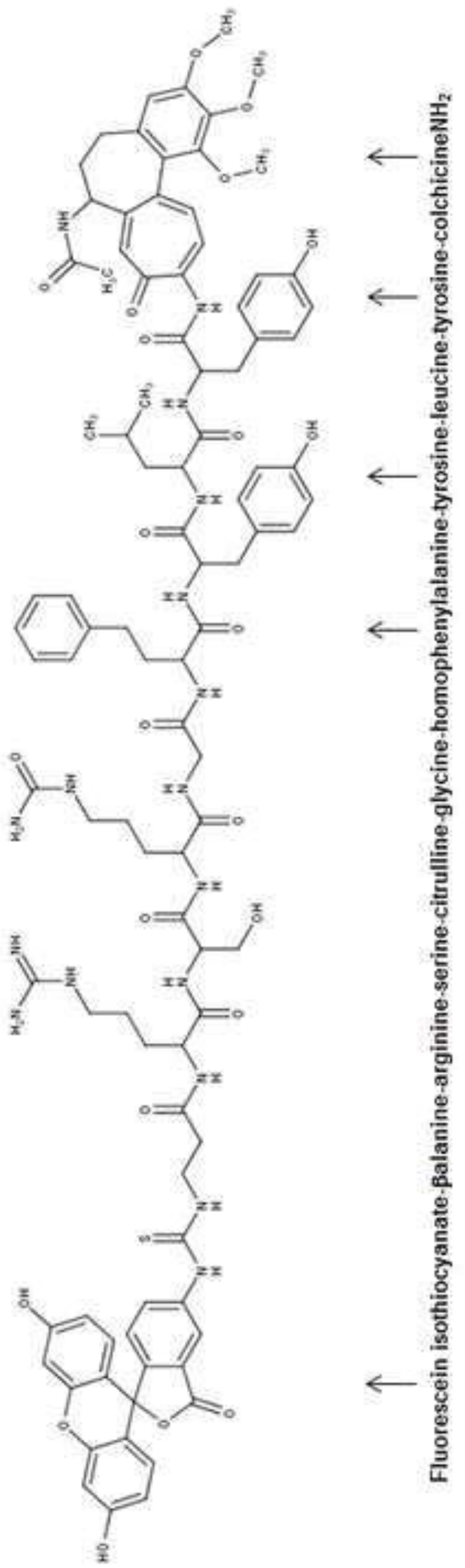


Figure(s)

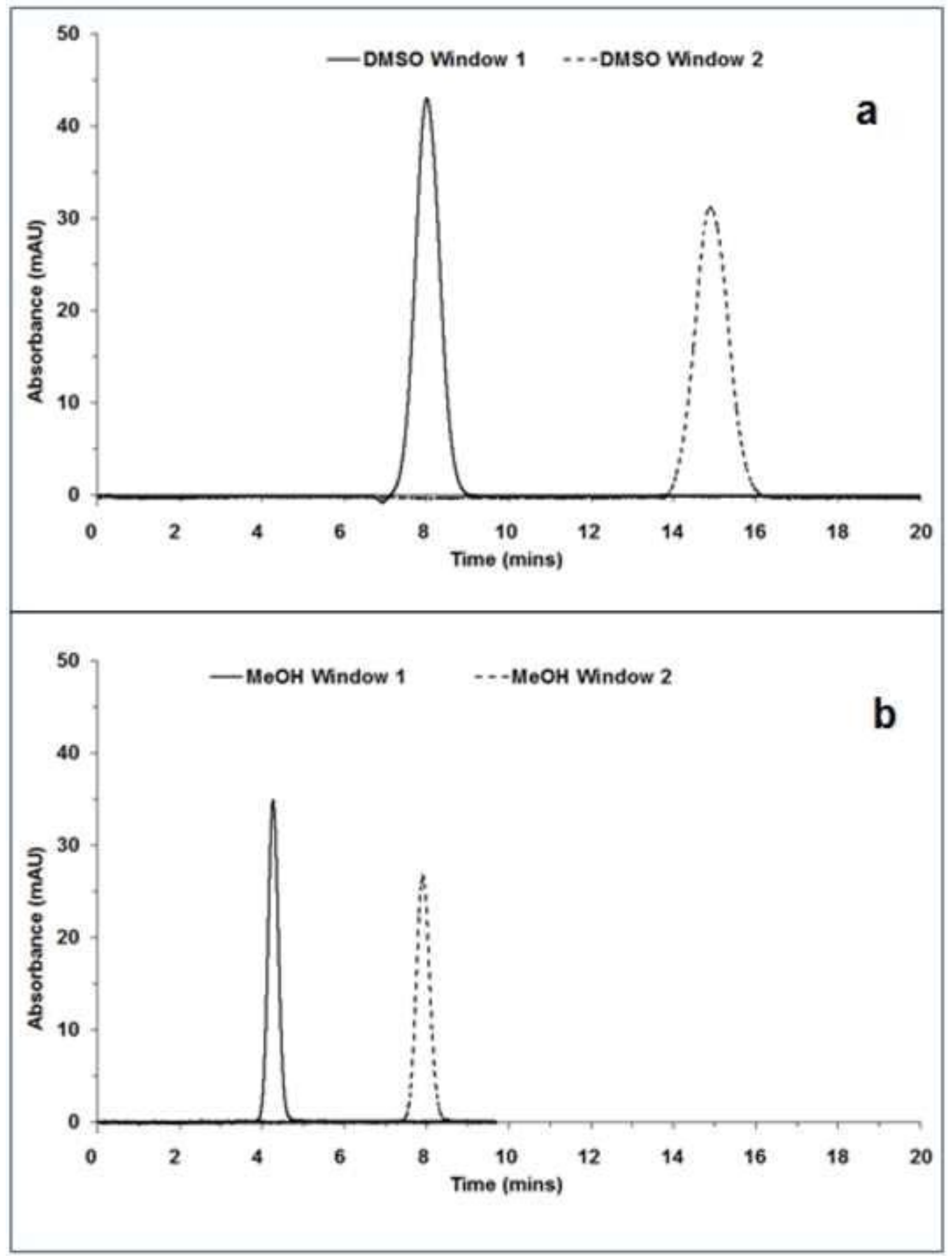




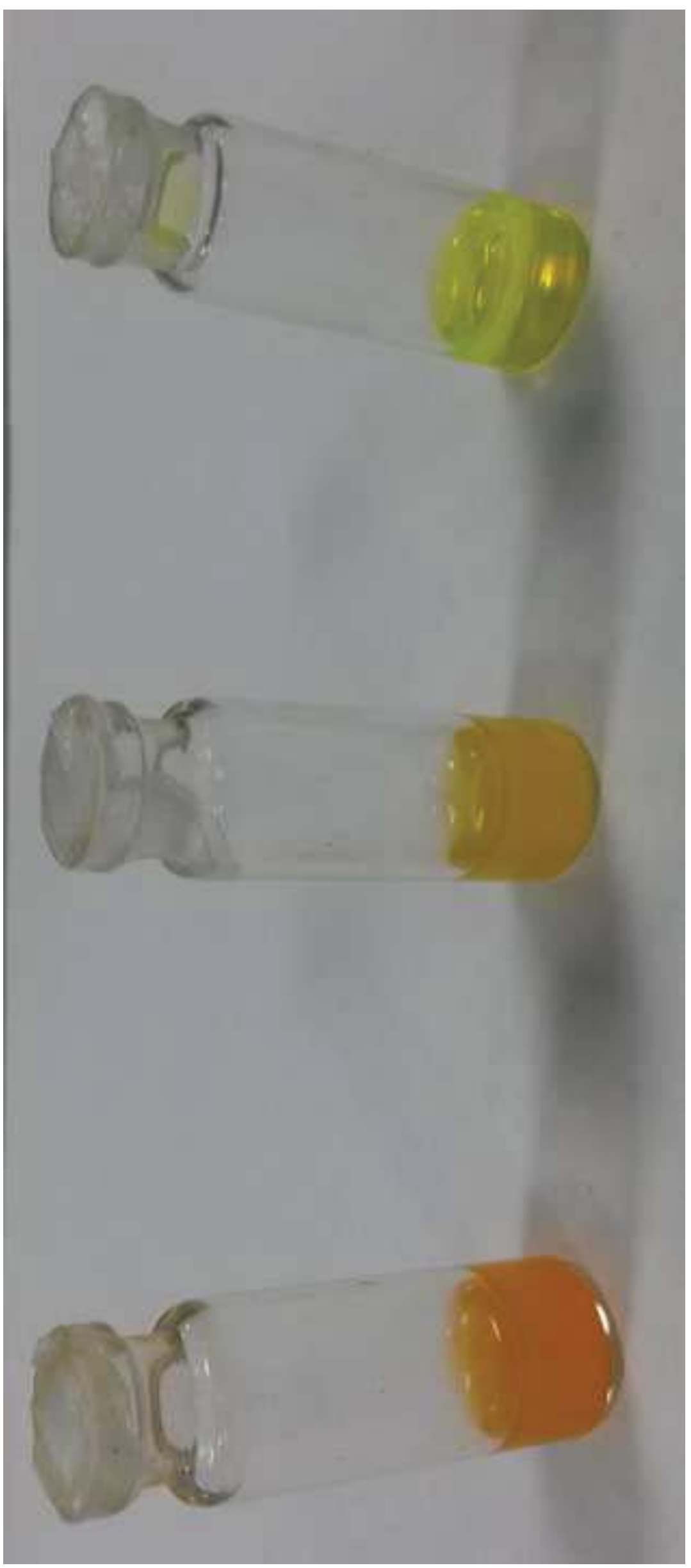

은 

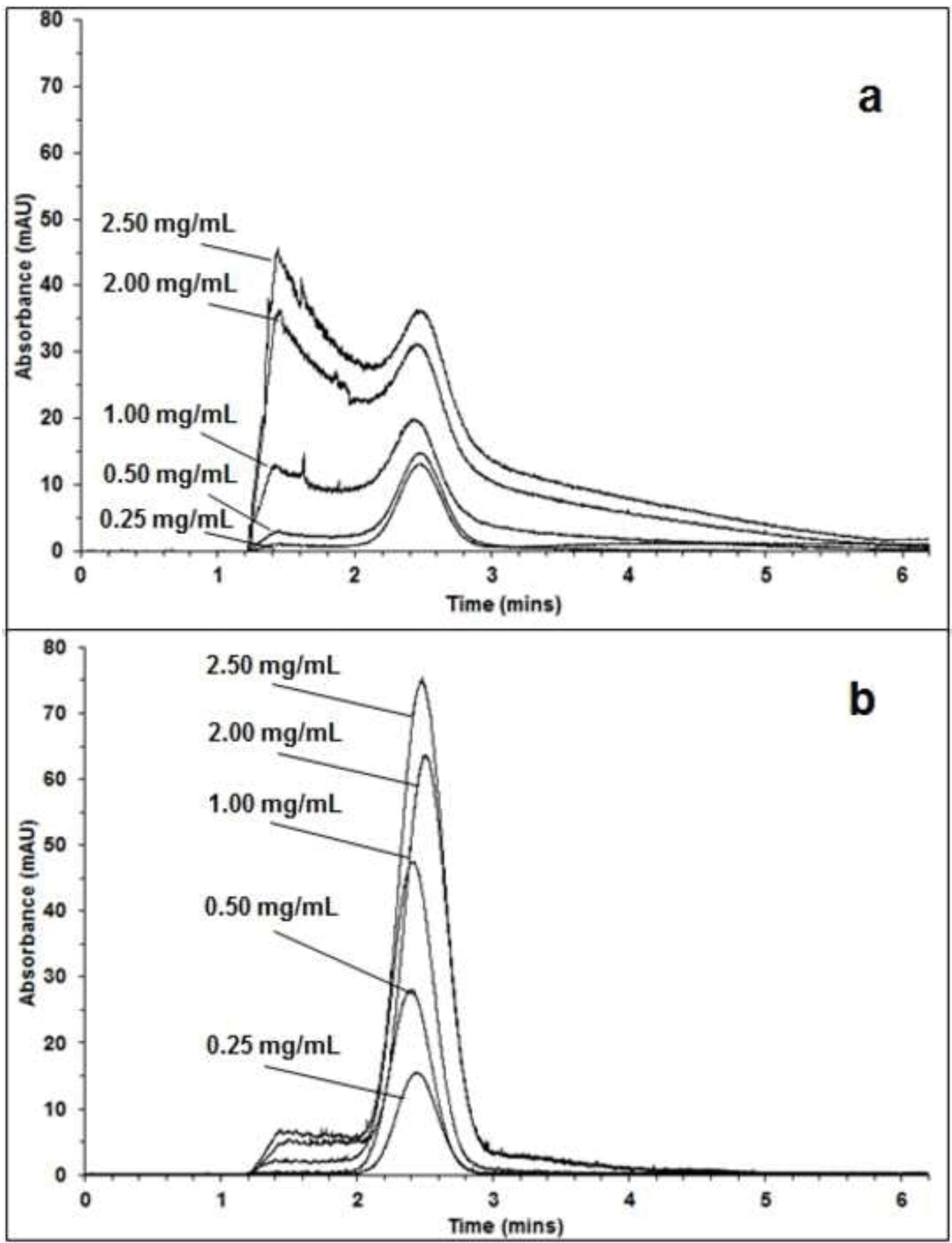


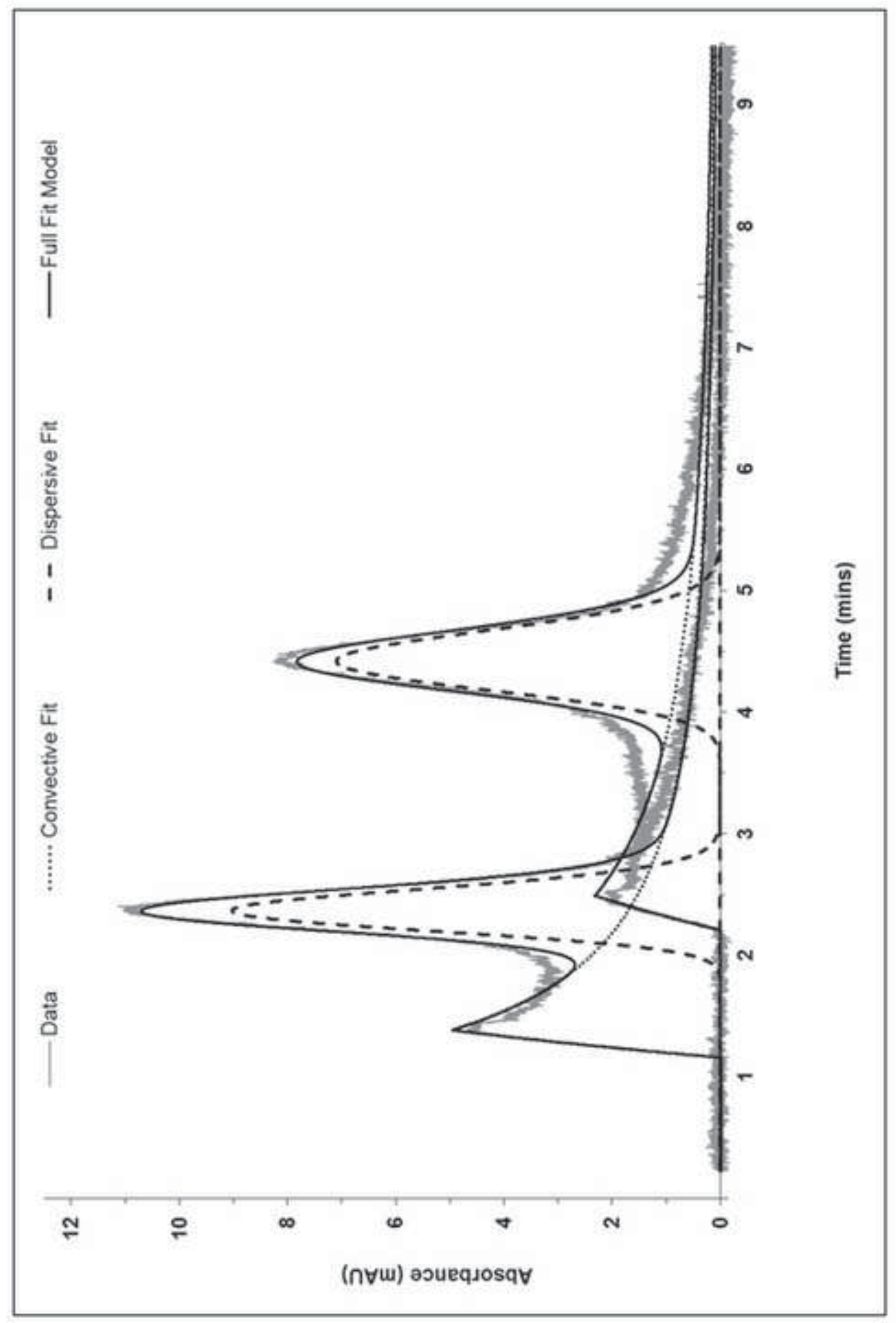




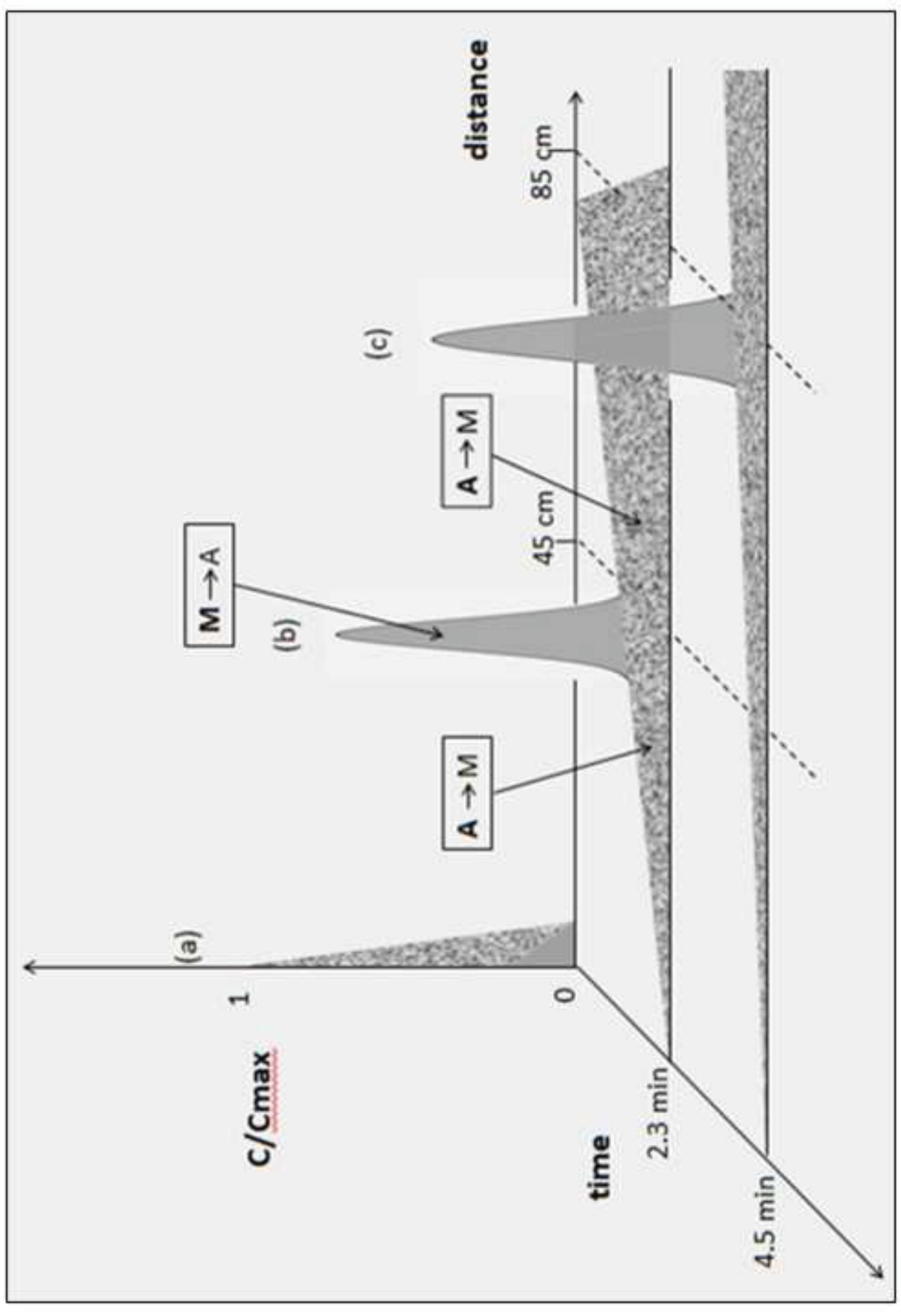


Figure(s)
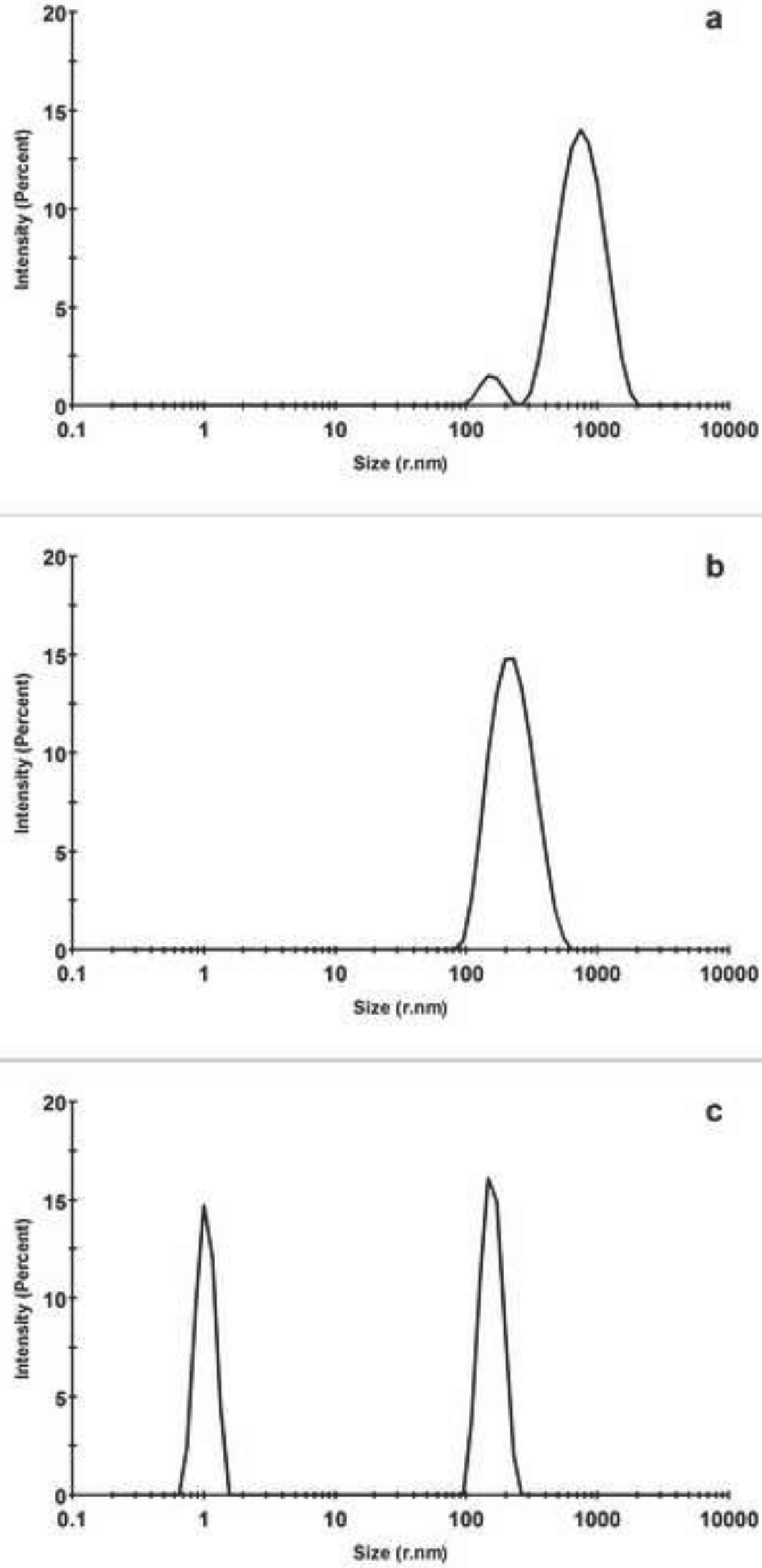


\section{List of Figures}

Fig. 1. Structure of ICT01-2588: in the sequence of functional groups, those with arrows are potential binding sites for cyclodextrins.

Fig. 2. Sizing records for ICT01-2588 in (a) DMSO at $1 \mathrm{mg} / \mathrm{mL}$, load and drive pressure 140 mbar and (b) methanol at $0.5 \mathrm{mg} / \mathrm{mL}$, load and drive pressure 70 mbar. Wavelength $280 \mathrm{~nm}$.

Fig. 3. Photograph of samples of ICT01-2588 at nominal concentrations $1 \mathrm{mg} / \mathrm{mL}$ in water (left), Tris buffer (centre) and Tris buffer with $10 \%$ HP- $\beta$-CD-s2 (right).

Fig. 4. Sizing records for ICT01-2588 at window 1 at concentrations $0.25,0.5,1,2$ and 2.5 $\mathrm{mg} / \mathrm{mL}$.

(a) Carrier medium Tris buffer with 10\% HP- $\beta$-CD-s1. Wavelength $490 \mathrm{~nm}$.

(b) Carrier medium Tris buffer with 10\% HP- $\beta$-CD-s2. Wavelength $280 \mathrm{~nm}$.

Fig. 5. Sizing records and data fitting for ICT01-2588 $0.5 \mathrm{mg} / \mathrm{mL}$ in Tris buffer with $10 \%$ HP- $\beta$-CD-s2. Wavelength $280 \mathrm{~nm}$. Primary data (grey) and fit (black) using model with dispersive (dashed) and convective (dotted) components.

Fig. 6. Schematic diagram of distance dependence of relative concentrations of monomer $M$, (solid grey) and aggregate, A, (stippled grey) at three time points: (a) on injection ( $\mathrm{t}=0$ ); (b) at time to window 1 at $45 \mathrm{~cm}$ for monomer $(\mathrm{t}=2.3 \mathrm{~min})$; (c) at time to window 2 at $85 \mathrm{~cm}$ for monomer $(\mathrm{t}=4.5 \mathrm{~min})$. All concentations normalised to the maximum value at the particular time point, and correspond to the conditions of Fig. 5.

Fig. 7. DLS data for (a) $2.5 \mathrm{mg} / \mathrm{mL}$ ICT01-2588 in Tris buffer with $10 \%$ HP- $\beta$-CD-s1, (b) 2.5 $\mathrm{mg} / \mathrm{mL}$ ICT01-2588 in Tris buffer with 10\% HP- $\beta$-CD-s2. (c) Tris buffer with 10\% HP- $\beta$ CD-s2. In each case, results are presented as size distributions by intensity. Viscosity 1.301 $\mathrm{mPa}$ s used in data processing. 